\title{
Purpose and Purposefulness at Work: The Impact on Employee Engagement and Organizational Commitment
}

\author{
Guangrong Dai \\ Korn Ferry \\ Signe Spencer \\ Korn Ferry \\ Susanne Blazek \\ Lirio
}

Purpose plays an important role in the construction of meaning and meaningfulness of work. This research examined the impact of purpose and purposefulness in the workplace. Study I developed a two-factor purposefulness at work survey and established a taxonomy of purpose through qualitative analysis of personal purpose statements. The model delineates eight types of personal purpose that range from being very self-centered to being very others oriented. The construct validity of the purposefulness at work survey and the robustness of the purpose taxonomy were tested in Study II. All purposes don't work equally. Others-oriented purposes were associated with higher level of purposefulness at work than were selforiented purposes. In turn, purposefulness was positively correlated with two work-related outcomes work engagement and organizational commitment. This paper advances the meaning and purpose literature by specifying purpose content and connecting personal purpose to employee experience.

Keywords: meaning of work, purpose of work, work engagement, organizational commitment

\section{INTRODUCTION}

If you were to get enough money to live as comfortably as you would like for the rest of your life, would you continue to work, or would you stop working? This is the question that has appeared on the General Social Survey conducted by the National Opinion Research Center at the University of Chicago since 1973. Over a 45-year period (1973-2018), the survey has found relatively stable results. On average about $70 \%$ of the respondents in the U.S. said they would keep on working. Work to many people is more than just a paid job and W-2 (Berg et al., 2010). It is an important part of their lives.

Frankl's (1959) Man's Search for Meaning catalyzed psychological studies on the meaning of life, with its assertation that an essential condition of being human is the desire to live meaningful lives. In recent years, research interest in meaning has proliferated among organizational scholars (Rosso et al., 2010; Rothausen \& Henderson, 2019). A breadth of personal and organizational consequences have been found to be associated with the perception of meaning and meaningfulness in work, including psychological well- 
being (Arnold et al., 2007), job satisfaction (Steger et al., 2012), work engagement (May et al., 2004); organizational identification (Pratt et al., 2006), performance (Kendall, 2019), and creativity (Cohen-Meitar et al., 2009).

Organizations today are the main home of the working individual (Dimitrov, 2012). Work has become a prominent domain in life. This is obvious by the amount of waking time we spend at work. Employees rely increasingly on their work to define their own meaning in life. Work has become more personal than ever, when what and how people do reflect who they are. However, work as a reliable source for meaningfulness is also weakening due to the fast pace of change in business. To adapt, organizations have to continuously transform how they operate. This translates to changing role responsibilities and demands on employee behaviors. These changes may create discrepancies between employees' worldview and working experience, which in turn could undermine meaning in life (George \& Park, 2017). The meaning crisis produced by this uncertainty may be further amplified by the increasing computerization of jobs (Frey \& Osborne, 2013). Questions about how employees make sense of the change and find the meaning in the ambiguous and stressful environment have important implications on employee well-being, motivation, productivity and organizational success (Burger et al., 2013; May et al., 2004; Sonenshein \& Dholakia, 2012).

While one could argue that organizations and leaders have an ethical or moral obligation to help people experience meaningfulness at work (Michaelson, 2005), others have established the business legitimacy to support employees' authentic self-expression as the means to elicit their best effort (Cable et al., 2013). The objective of this paper is to contribute to the meaning and purpose literature by advancing our understanding of individual purposes. Specifically, we will investigate what types of purpose people identify and pursue, how different types of purpose affect the feeling of purposefulness at work, and how they impact work engagement and organizational commitment.

\section{MEANING AND MEANINGFULNESS}

Meaning and meaningfulness tend to be used interchangeably in the literature (Rosso et al., 2010). They relate to each other but are distinct. Meaning is the mental representation of possible relationships among things or events. It is the output of having made sense of something (Pratt \& Ashforth, 2003). The desire for sense making implies the basic belief that there is coherence and order in the world. Sense is made when the object or situation is understandable or comprehensible to the individual, therefore validates such belief. Why does this happen? Why do I do this? Meaning-making involves constructing an explanation for life encounters. The drive to search for meaning reflects people's need for certainty. The brain likes to know what is going on by recognizing patterns in the world. It likes to feel certain (Herbert, 2010). Research has shown that meaning in life reports are sensitive to the presence of reliable pattern or coherence in environmental stimuli (Heintzelman et al., 2013). In one of their studies, participants were presented with 16 pictures of trees including four for each of the four seasons. The researchers manipulated the order of the pictures. The 16 pictures appeared in a random order to one group but followed the change in seasons to another group. Participants who had seen the pictures in the seasonal pattern condition reported higher levels of meaning in life than those in the random experimental condition. This finding supports the hypothesis that sense making influences the perception of meaning. Meaning is characterized by regularity, predictability, and reliable connections.

While meaning is the cognitive interpretation of the matter of concern, meaningfulness has an evaluative connotation. Meaningfulness relates to determining the value or worth of an event (May et. al., 2004). Something must be perceived to be significant or important for it to be meaningful. The construct of meaningfulness can be "seen as a feeling that one is receiving a return on investment of one's self in a currency of physical, cognitive, or emotional energy" (Kahn, 1990, pp.704-705). It is an individual's idiosyncratic evaluation of worthwhileness. The greater amount of perceived or felt significance of something, the higher meaningfulness it has. Two conditions therefore are prerequisite to meaningfulness: meaning made and felt significance. Some instruments for measuring meaning in life contain these two components (e.g., George \& Park, 2016; Reker \& Wong, 1988). Likely, they are considered core 
dimensions in measuring meaningful work by organizational and career scholars (Steger et al., 2012). These authors define meaningful work not as simply whatever work means to people, but as work that is significant and positive in valence.

\section{THE ROLE OF PURPOSE IN MEANING AND MEANINGFULNESS PERCEPTION}

Meaning and purpose are inherently related. In fact, Frankl himself used meaning and purpose interchangeably (Damon et al., 2003). Instruments that intended to operationalize Frankl's concept of meaning in life often blended purpose with meaning. For instance, one of the early instruments - The Purpose in Life Test, measures "the degree to which the subject experiences a sense of meaning and purpose in life" (Crumbaugh, 1968, p.74). The other early instrument, The Psychological Well-Being by Ryff(1989) has a sub-scale, the Purpose in Life. This subscale measures "the feeling there is purpose in and meaning to life" (Ryff, 1989, p.1071). More recently, Steger, Frazier, Oishi, and Kaler (2006) designed the Meaning in Life Questionnaire that assesses two factors - presence of meaning and search for meaning. In this instrument, items like "My life has a clear sense of purpose" are combined with "I understand my life's meaning" to indicate the current level of meaning in life. Similarly, items like "I am always looking to find my life's purpose" and "I am seeking a purpose or mission for my life" are used to signify the degree to which one is searching for meaning.

The pursuit of a purpose provides life with meaning. As discussed above, meaning making is prerequisite to the feeling of meaningfulness. Purpose relates to meaning and meaningfulness as it affects the sense-making process.

Meaning is pliable such that the same object or action could have different kinds of meaning for different people (Baumeister, 1991). In other words, it is subjective (Pratt \& Ashforth, 2003). People can derive different meanings from almost any job. Even in the same job in the same organizational setting, there are differences in how people can make meaning of their work (Wrzesniewski, 2003). Similarly, perceptions about meaningfulness are ultimately determined by each individual, although they are influenced by the objective environment. A single work experience may be perceived as very meaningful by one person, but not much by another (Rosso et al., 2010).

Cuba born American novelist Anaïs Nin once wrote, "we don't see things as they are, we see them as we are." Meaning is a constructed experience (King, 2012). It is influenced by the individual's self-concept or self-identity. People go through life holding certain beliefs and goals (Baumeister, 1991). Self-concept or self-identity consolidates one's beliefs, values, and goals into a coherent story that serves as the basis for interpreting situations and making decisions. The constellation of the beliefs, values and goals is also known as the orienting system (Park, 2010; Wrzesniewski, 2003). Orienting systems provide people with cognitive frameworks through which experiences are interpreted. To the extent the appraised meaning matches an individual's orienting system, the person feels he/she understands the situation.

To the contrary, the discrepancy between the appraised meaning and an individual's self-concept undermines the sense of meaning and meaningfulness (George \& Park, 2017). The classical Cognitive Dissonance Theory posited that people are motivated to maintain consistency among their beliefs, attitudes, and behaviors (Festinger, 1957). Disruptions in beliefs and goals serve as a driving force that compels the mind to acquire new beliefs or modify goals in order to reduce the distress produced by the discrepancy. In other words, individuals are strongly motivated to make sense of situations that violate their orientation systems. Real life is full of absurdity and mysteries. Meaning-making attempts following stressful and unexpected life events are very common. Nearly two thirds $(68.4 \%)$ of the sampled adults in the US reported some efforts to searching for meaning in the attacks two months post-9/11 (Updegraff et al., 2008).

Purpose is a goal of sorts. In the next section, we will discuss the relationship between the two. But for now, they are synonymous. Purposes or goals refer to cognitive representations of desired states or endpoints that energize and guide behaviors. They are the integral part of one's self-concept. Having clear purposes is important to the establishment of a coherent personal identity. Together with other constructs such as beliefs and values, purpose outlines for how things are in the world and what is worth striving for (George \& Park, 2017). Purpose contributes to meaning and meaningfulness as it helps people make sense 
of life experiences and gives them a sense of direction and significance in their lives. Rosso et al. (2010) in their theoretical framework described purpose as one of the mechanisms to explain the processes through which work comes to be meaningful.

Investigating the influence of meaningful work on employee wellbeing and work-related outcomes has growing relevance to organizations, managers, coaches, and employees (Steger et al., 2012). However, traditional approaches, mainly the Job Characteristic Model (Hackman \& Oldham, 1976) focuses on job qualities such as skill variety, task identity, task significance, autonomy and feedback as the antecedents of meaningfulness. Following this model, managers use techniques such as job enrichment to supply and enhance meaningfulness and the motivational potency of work. The meaning in life literature, on the other hand, stresses the subjective nature of meaning and meaningfulness. Lips-Wiersma and Morris (2009) posited that meaning comes from within. Employees actively, and on an ongoing basis, evaluate the work in relation to their inner compass to determine its meaningfulness. Our research intends to fill the void in the meaningful work literature by shifting the attention to purpose, one of the individual factors that affect meaning and meaningfulness perception.

\section{Types of Purpose}

Scholars have tried to develop theoretic models to describe purposes. One theory proposed a hierarchical structure of human goals (Chulef et al., 2001). The hierarchical organizing of human goals assumes the progressive abstractness of goals from the low to the high level. Goals at the bottom of the hierarchy tend to be specific, concrete and time-constrained, while those on the top of the hierarchy tend to be abstract, far-reaching, and timeless. In the literature, purposes often refer to those high-level goals that represent ultimate aspirations or grand missions, while low-level goals are considered specific actions or steps to achieve higher purposes (Carton, 2018). Higher purpose give meaning to short-term, specific goals. This hierarchical organization of human goals has received empirical support (Bagozzi et al., 2003). These researchers interviewed nearly 600 participants for their motives for joining the Italian Army. Using a social network analytic method, the research found that the 43 categories of motives can be organized into three groups of master motives - social motives, intrinsic motives, and extrinsic motives. Specific motives in each group are further organized in a hierarchical structure. For instance, in the extrinsic cluster, viewing the army as a job opportunity serves the goal of financial security, financial security supports the desire for a secure future, and a secure future then assures that family responsibilities would be looked after.

One study conducted in the educational environment is particularly noteworthy. Yeager and Bundick (2009) intended to understand how work goals students have for their futures promote meaning in schoolwork during adolescence. They interviewed 148 middle and high school students for their work goals and the reasons why they matter to them. The coding process resulted in the establishment of a framework of purposes. Various work goals differ in two dimensions - self-oriented versus beyond-the-self-oriented, intrinsic versus extrinsic. Their research found that beyond-the-self-oriented goals, in other words, selftranscendent goals were associated with higher levels of meaning in school life. The self- versus othersorientation demarcation is a consistent theme in meaning research (Lips-Wiersma \& Morris, 2009; Rosso et al., 2010).

The first objective of this research was to explore and build a taxonomy of individual purposes. Our research replicates Yeager and Bundick (2009) work but uses adult participants. We will investigate typical purposes adults have, and how different types of purpose relate to abstractness and self-versus-other orientations.

\section{Purposefulness at Work}

The second objective was to develop and validate a survey of purposefulness at work. According to Merriam-Webster's dictionary, being purposeful means having purpose and being full of determination. Purposefulness describes the extent to which individuals are dedicated to a cause. It also means how much individuals approach their work as a way that ties to a sense of purpose. In the Goal Setting Theory, goal commitment is a critical factor. A goal would have little motivational effect without the commitment to it (Locke \& Latham, 1990). A meta-analytic study confirmed the importance of goal commitment in goal 
setting (Klein et al., 1999). The same logic applies to purpose. Having a purpose is different than acting on a purpose. For one to live a purpose, he/she must first perceive a purpose, then have the motivation and access to opportunity to pursue that purpose.

Some purposes are oriented toward promoting self-interest; others are self-transcendent, oriented toward something bigger than self. Some purposes concern ultimate aspirations that reflect enduring values; others focus on more specific and near-term outcomes. They may be congruent with organizational missions to different degrees. They may receive different support in organizations. The variation in abstractness and the access to opportunity could result in different levels of purposefulness. Yeager and Bundick (2009) in their research only considered intrinsic and beyond-the-self-oriented work goals as purposeful. But their research didn't measure purposefulness to validate their proposition. In this research we investigated how different purposes related to the perception of purposefulness.

\section{Impact on Work Engagement and Organizational Commitment}

Our next research objective was to investigate the impact of purposes and purposefulness on workrelated outcomes, particularly work engagement and organizational commitment. The traditional management model, formed in the early industrial age, is oriented toward maximizing performance efficiency through standardization and consistency. A notable feature of this traditional management philosophy is that rules and regulations should be well defined and applied uniformly to avoid involvement of personalities and preferences of employees. One recent study, however, has shown that allowing employees opportunities for authentic self-expression delivers better organizational outcomes than traditional people management practices that emphasize the fit in of employees to organizational norms and identities (Cable et al., 2013). These positive outcomes include increased customer satisfaction and employee retention. This finding is consistent with the research on "job crafting." Job crafting refers to the proactive behavior employees take to redesign their jobs in order to increase the meaning of work and the feeling of purpose (Berg et al., 2010). Job crafting has been related to many beneficial organizational outcomes, most noticeably job satisfaction and work engagement (Rudolph et al., 2017). The shift towards a more personalized job-crafting approach may reflect changes in the nature of most work, from routinized, predictable work toward work requiring flexibility, innovation, and changing solutions to novel problems, i.e. toward types of work in which the engagement of individual preferences is more appropriate.

Purposefulness denotes approaching work in a way that express individual purposes. In line with the research findings reviewed above, we expect positive impact of purposefulness on work engagement and organizational commitment. To the extent individuals feel purposeful about their work, they should be more engaged and committed to their organizations. Since different purposes related to purposefulness to different degrees, our research will also investigate how work engagement and organizational commitment vary across different types of purposes.

\section{STUDY I}

The objective of Study I was to develop a purposefulness at work survey instrument and collect quantitative data to identify and build a taxonomy of purposes.

\section{Participants}

Participants were recruited from two resources: the Qualtrics Sampling Service and a subsidiary office of a professional service firm in Boston. The Qualtrics sample contained some unemployed and part-time employed participants. Recruiting participants from the second source was intended to balance the makeup of employment status. Steps were taken to ensure the quality of the responses. First, we examined the response time. Surveys with unreasonably short response time were eliminated. Second, we read through responses to open ended questions. Those that contained incomprehensible expressions or random words were removed. Third, we calculated the variance of responses across survey items. Surveys with no or very small variance suggested a high likelihood that participants inattentively clicked through survey items. Those response were also excluded. The ultimate sample size is 333. About two thirds of the participants 
were females. Table 1 presents sample distributions on age, education, employment, and position levels. The data that support the findings of this study are available from the corresponding author upon reasonable request.

\section{TABLE 1
DEMOGRAPHIC DISTRIBUTION}

\begin{tabular}{|c|c|c|c|}
\hline Demographic & Category & $\begin{array}{l}\text { Percentage in } \\
\text { Study I }\end{array}$ & $\begin{array}{c}\text { Percentage in } \\
\text { Study II }\end{array}$ \\
\hline \multirow{7}{*}{ Age } & Under 20 & 2.4 & 0.0 \\
\hline & 20 's & 17.4 & 11.0 \\
\hline & 30 's & 25.5 & 35.0 \\
\hline & 40 's & 17.1 & 28.5 \\
\hline & 50 's & 17.1 & 16.8 \\
\hline & 60 's & 15.3 & 7.8 \\
\hline & 70 and above & 5.1 & 0.9 \\
\hline \multirow{7}{*}{ Education } & Some secondary/high school & 7.2 & 0.1 \\
\hline & Secondary/high school graduate & 19.8 & 14.0 \\
\hline & Trade/technical education & 15.0 & 7.9 \\
\hline & Associate's degree/diploma & 11.1 & 18.7 \\
\hline & Undergraduate degree (Bachelor's, etc.) & 30.0 & 39.5 \\
\hline & Postgraduate degree (Master's, etc.) & 12.3 & 16.3 \\
\hline & Doctorate/professional (PhD., M.D., etc.) & 4.5 & 3.4 \\
\hline \multirow{7}{*}{ Position Level } & Entry level individual contributor & 30.3 & 19.0 \\
\hline & Senior level individual contributor & 20.1 & 23.8 \\
\hline & First level manager or supervisor & 24.3 & 33.5 \\
\hline & Manager of managers & 8.7 & 8.7 \\
\hline & Functional leader & 6.3 & 8.1 \\
\hline & Business unit leader & 3.0 & 2.1 \\
\hline & Executive & 6.6 & 4.0 \\
\hline \multirow{5}{*}{ Employment } & College Student & 4.5 & \\
\hline & Unemployed & 17.7 & \\
\hline & Part-time employed & 15.9 & \\
\hline & Full-time employed & 48.3 & 100.0 \\
\hline & Retired & 13.5 & \\
\hline
\end{tabular}

\section{Measures}

Purposefulness at Work

A panel of four talent management professionals was formed to conceptualize the purposefulness assessment. Two of them have Ph.D degrees in Industrial and Organizational Psychology. The other two have MBAs and experience of over 15 years in leadership development and coaching. Through extensive discussion, the panel identified the following five assessment themes that might reflect an individual's perception of purposefulness. They are (1) Awareness, to what extent an individual is aware of his/her purpose; (2) Commitment: to what extent an individual is committed to or feel passionate about the purpose; (3) Internal coherence: to what extent an individual's actions align with the purpose; (4) Socially 
compatible: to what extent an individual's purpose is cohesive with the social context the person is embedded in; (5) Organizationally compatible: to what extent an individual's purpose is compatible with the organization's mission and purpose. Fifteen items were developed to operationalize this model of purposefulness. Each theme had three items. Participants were asked to rate to what extent they agree with the items using sliders that ranged from Strongly Disagree (1) to Strongly Agree (5).

\section{Purpose Statement}

We solicited individual purposes by asking participants to free-write their personal purpose statement. The survey instructed participants' thinking toward relatively lasting ambitions or intentions instead of immediate results or objectives one wants to accomplish, such as passing a certification exam or meeting a sales target. In the survey introduction, we define personal purpose as "what you want to focus on, what you want to accomplish, what kind of impact you want to generate, or who you want to become in a particular area of your life."

\section{Results}

Initially, the exploratory factor analysis (EFA) of the purposefulness survey data yielded three factors. A few items had high cross-factor loadings, which were removed from further analysis. The EFA was then conducted on the remaining items. This analysis generated a two-factor solution. Together they explained $60.02 \%$ of the measurement variance. We named them Clarity and Compatibility (see Table 2 for items and item-factor loadings). Both factors have adequate internal reliability. Clarity reflects how much an individual is clear and passionate about his/her purpose. Compatibility describes to what extent an individual has a purpose that matches with the organizational and social context. The mean score was 3.68 $(S D=0.76)$ for clarity, 3.32 for compatibility $(S D=0.98)$. The difference was about 0.41 standard deviations. The correlation between the two factors is 0.51 .

TABLE 2

TWO FACTORS OF THE PURPOSEFULNESS SURVEY

\begin{tabular}{lcc}
\hline Item & $\begin{array}{c}\text { Compatibility } \\
\alpha=0.90\end{array}$ & $\begin{array}{c}\text { Clarity } \\
\alpha=0.78\end{array}$ \\
\hline I know what I am most passionate about in my life & 0.05 & $\mathbf{0 . 6 8}$ \\
My personal purpose fits into my organization's mission & $\mathbf{0 . 8 6}$ & 0.12 \\
I know what I'd like to be remembered/ known for & 0.18 & $\mathbf{0 . 6 8}$ \\
Following my personal purpose also helps the organization & $\mathbf{0 . 8 8}$ & 0.22 \\
where I work & & 0.38 \\
Working toward my personal purpose makes me a good team & $\mathbf{0 . 7 0}$ & 0.23 \\
member & $\mathbf{0 . 8 5}$ & 0.18 \\
Working in my organization gives me opportunities to realize & & $\mathbf{0 . 7 6}$ \\
my personal dreams & & $\mathbf{0 . 6 8}$ \\
My personal purpose is compatible with values of others with & 0.21 & $\mathbf{0 . 8 1}$ \\
whom I work & 0.24 & $\mathbf{0 . 6 8}$ \\
I give up some things to do things I am passionate about. & 0.28 & \\
There is a purpose that attracts my attention and effort & & \\
I have found significant ways to offer my gifts and talents to \\
the world
\end{tabular}

Several steps were taken to analyze personal purposes and develop a purpose taxonomy. First, two of the authors independently read all the purpose statements to come up a list of themes. The two lists were compared and discussed. The two researchers identified some common themes. Discrepancies occurred mostly due to different levels of abstraction that the two researchers used to group responses. For instance, topics around religion appeared multiple times. Religion therefore was identified as a categorizing theme 
by one researcher. The other researcher, however, considered this a subtheme of a broader concept-a principled life, which represent a desire to live the life according to or expressing certain values or beliefs. Similarly, concerns about health and financial issues were subsumed under basic needs, which tend to be more inclusive than those specific needs. Through discussion and calibration, the researchers eventually arrived at a list of eight categories. See Table 3 for descriptions.

TABLE 3

EIGHT PURPOSE TYPES

\begin{tabular}{lll}
\hline Theme & Description & Example \\
\hline Advocating & $\begin{array}{l}\text { Supporting or sponsoring a cause or } \\
\text { issues }\end{array}$ & $\begin{array}{l}\text { Raising awareness of domestic } \\
\text { violence }\end{array}$ \\
\hline Basic needs & $\begin{array}{l}\text { The need for money, health, housing, } \\
\text { etc. }\end{array}$ & Staying healthy while aging \\
\hline Benevolence & Serving or helping others & $\begin{array}{l}\text { Providing shield to homeless } \\
\text { people }\end{array}$ \\
\hline Career & Personal success and accomplishment & $\begin{array}{l}\text { Being able to achieve what I set } \\
\text { out to }\end{array}$ \\
\hline Family & Attention to family life & Being there with my family \\
\hline Personal growth & Growing and developing myself & Overcoming my fears \\
\hline Principled life & $\begin{array}{l}\text { Living a life that expresses certain } \\
\text { values or beliefs }\end{array}$ & $\begin{array}{l}\text { Treat people as I would want to } \\
\text { be treated }\end{array}$ \\
\hline Quality life & $\begin{array}{l}\text { Desired experience such as well-being } \\
\text { and life style }\end{array}$ & \begin{tabular}{l} 
Travel the world \\
\hline
\end{tabular} \\
\hline
\end{tabular}

The researchers then assigned participants' purpose statements to the eight purpose types. To assist the classification, coding instructions were developed. A coding instruction defines the category, then identifies subthemes and provides some examples. Table 4 uses benevolence as an example to illustrate.

TABLE 4

CODING INSTRUCTION FOR BENEVOLENCE

Definition: serving or helping others

\begin{tabular}{ll}
\hline Subthemes & Examples \\
\hline Be specific about whom to serve & $\circ$ Animals \\
& $\circ$ Homeless people \\
& $\circ$ Patient with mental disorder \\
& $\circ$ Older adults \\
& $\circ$ Small businesses \\
\hline Be specific in what way to serve & $\circ$ Make people feel good by telling jokes \\
& $\circ$ Make people happy with singing \\
\hline Take specific roles & $\circ$ Work as a social worker \\
& $\circ$ Become a foster care-er \\
& $\circ$ Mentor women \\
\hline To achieve certain results & $\circ$ Help people see their strengths \\
& $\circ$ Help people become stronger physically \\
& $\circ$ Help others achieve balance and joy in their lives \\
\hline Describe as personal characteristics or & $\circ$ Be a good-hearted person \\
virtues & $\circ$ To be kind \\
\hline
\end{tabular}




\begin{tabular}{ll}
\hline & $\circ$ To be helpful to others \\
& $\circ$ Being generous, loving \\
\hline Serve people in general, not specific of & $\circ$ Help as many people as I can \\
"how" to serve & $\circ$ Make people happy \\
& $\circ$ Make a positive impact on people \\
& $\circ$ Make a difference in people's lives \\
\hline
\end{tabular}

Once the instructions were developed, two researchers independently coded individual purpose statements to the eight purpose types. They agreed on $83.8 \%$ of the categorization, achieving a high level of inter-rater agreement. This suggests the eight purpose types provide a reliable taxonomy that can adequately categorize individual purposes.

\section{Summary and Discussion}

In study I, a survey of purposefulness was pilot tested. Purposefulness at work contains two factorsclarity and compatibility. Clarity denotes the sense of having a purpose. To be purposeful at work, however, individuals also need to be able to live the purpose. Compatibility reflects the social embeddedness of personal purpose in the organizational context. To the extent individuals perceive the congruence between their personal purposes and the working environment, they feel it legitimate and supported to pursue their personal dreams. The two factors are moderately correlated, suggesting both are defining components of purposefulness at work.

Personal purpose appears to be idiosyncratic. Every individual has their distinct pursuits and aspirations. Our qualitative analyses of the free writings of personal purposes, however, revealed that a definite number of purpose categories can sufficiently represent the variations among people. While purposefulness signals a person's level of intentionality, the taxonomy of purpose allows the investigation of content - what really attracts people's attention. It also provides the foundation for further empirical study of the unique impact of different types of purposes.

\section{STUDY II}

The objective of this study was to validate the purposefulness survey and the taxonomy of purpose by investigate the intercorrelations among these variables and their impact on work engagement and organizational commitment.

\section{Participants}

This sample of participants was recruited through Amazon's MTurk. Complete responses were collected from 879 participants. The same steps were taken to ensure the quality of returned surveys. This time, gender was about equally distributed among males and females and all participants described themselves as fully employed. Table 1 reports the sample distributions on age, education and position. The data that support the findings of this study are also available from the corresponding author upon reasonable request.

\section{Measures}

Purposefulness at Work

The 10 items derived from Study I were used in Study II to measure purposefulness. Similar to Study I, participants were asked to rate to what extent they agree with the items using sliders that ranged from Strongly Disagree (1) to Strongly Agree (5).

\section{Personal Purposes}

The same method was used in Study II to ask participants to free-write their personal purpose statements. In addition, participants were asked to reflect on their purposes and respond to several questions about their purposes. 
Purpose Type

Participants were asked to indicate which one of the eight types of purpose derived from Study I describes their personal purposes. It was a single answer multiple-choice question.

\section{Timeframe}

Participants were asked to indicate which timeframe their purposes are about. Do they refer to nearterm goals or very long-term aspirations? There were five options: a few weeks or months, a few years, a decade, several decades, and the rest of my life.

\section{Frame of Reference}

Participants were asked to indicate whom their purposes mostly affect. Do they tend to address personal issues or something beyond self-interest? There were six options: myself, family or nearby group, other people, the community or region, the nation, and the world.

\section{Work Engagement and Organizational Commitment}

An off-shelf instrument was used to assess work engagement and organizational commitment (Lewis, 2015). This instrument used forced-choice IRT methodology (FC-IRT) to control response distortion (Brown \& Maydeu-Olivares, 2011). The 20 items are placed in 5 blocks. Each block has four items, half of them are engagement items, the other half are commitment items. The instrument has equal numbers of positively and negatively worded items. Participants were asked to rank the four statements in each block from most like them to least like them. The two scales have adequate reliabilities (see Lewis, $2015 ; r^{\prime}{ }_{t t}=$ .82 for work engagement, $r^{\prime}{ }_{\text {tt }}=.79$ for organizational commitment). In addition to the off-shelf instrument, we also administered two extra items asking participants to rate how much they would recommend their current organizations to families or friends as the places to work, and how long they expect to continue to work for that organization. The composite of the two items had very strong correlations with the FC-IRT method, particularly the organizational commitment scale $(r=0.69)$, which provides the support to the construct validity of the FC-IRT measure.

\section{Results}

The two-factor model of the purposefulness survey was replicated in Study II. The result of the confirmatory factor analysis suggested an acceptable fit of the measurement model, $\chi^{2}(d f=34)=266.78$, $\mathrm{CFI}=.95, \mathrm{TLI}=.93$, $\mathrm{RMSEA}=.09(90 \% \mathrm{CI}=.08-.10)$, standardized root mean square residual $=.05$. Once again, the two sub-scales demonstrated high reliabilities ( $\alpha=0.80$ for clarity, $\alpha=0.90$ for compatibility). The mean score was $3.81(S D=0.75)$ for clarity, and 3.55 for compatibility $(S D=0.98)$. The difference was about 0.30 standard deviations. The correlation between the two factors was $r=0.56$.

In Study II, the free writing of personal purposes was used to prompt the participants to anchor their responses to subsequent questions. One of the questions asked participants to characterize their purposes into one of the eight purpose types derived from the qualitative analysis of purpose statements collected in Study I. Table 5 provides the distribution of purpose types selected by the participants. As can be seen, benevolence represents the most frequently selected purpose, which contrasts against basic needs as the least selected option. 
TABLE 5

DISTRIBUTION OF PURPOSE TYPE IN STUDY II

\begin{tabular}{lc}
\hline Purpose Type & Percentage \\
\hline Advocating & $11 \%$ \\
Basic needs & $2 \%$ \\
Benevolence & $27 \%$ \\
Career & $6 \%$ \\
Family & $17 \%$ \\
Personal growth & $8 \%$ \\
Principled life & $17 \%$ \\
Quality life & $10 \%$ \\
Others & $2 \%$ \\
\hline
\end{tabular}

If the taxonomy reflects something real about people's purpose, then there should be sensible differences, by purpose type, in the extent to which the person sees his/her purpose affecting self or others. There might also be reasonable differences in timeframe. To test this, ANOVA were conducted comparing different types of purpose on these two ratings (whom to impact and timeframe). The results are reported in Table 6 . The differences were statistically significant on the rating of whom to impact $\left(F_{(7,793)}=22.66\right.$, $p<.001)$ and timeframe $\left(F_{(7,794)}=3.61, p<.01\right)$. The literature regarding self- versus others-orientation was supported by this study. Two purposes-Advocating and Benevolence are clearly others-oriented, while Personal Growth and Quality of Life tend to be more self-oriented. The analysis also supported the literature regarding the time orientation. Principled Life and Quality Life describe how people choose to live their lives. They refer to means rather than ends, therefore are long-term oriented. To the contrary, Career and Basic Needs have shorter time frame. They tend to describe near-term goals.

TABLE 6

MEANS ON SCOPE OF IMPACT AND TIMEFRAME BY PURPOSE TYPE

\begin{tabular}{lrc}
\hline Purpose Type & Whom to impact & Timeframe \\
\hline Advocating & 4.68 & 4.22 \\
Basic Needs & 3.25 & 4.15 \\
Benevolence & 4.05 & 4.52 \\
Career & 3.49 & 3.96 \\
Family & 2.62 & 4.40 \\
Personal growth & 2.77 & 4.29 \\
Principled Life & 3.82 & 4.60 \\
Quality life & 2.77 & 4.57 \\
\hline
\end{tabular}

Next, we examined the relationship between different purpose types and purposefulness. ANOVA were conducted comparing different purpose types on the overall rating of purposefulness and on each factor. Table 7 reports the mean scores across the eight types of purpose. The mean differences are statistically significant for purposefulness $\left(F_{(7,795)}=6.31, p<.001\right)$, clarity $\left(F_{(7,795)}=6.07, p<.001\right)$, and compatibility $\left(F_{(97,795)}=4.72, p<.001\right)$. It is interesting to notice that clarity has the highest rating on advocating purpose, while compatibility has the highest rating on career. It appears career purpose is more likely to receive support and access to opportunity in organizations than other purposes. Two self-oriented purposes, basic needs and quality life have lowest ratings on purposefulness. 
TABLE 7

MEANS ON PURPOSEFULNESS AND TWO FACTORS BY PURPOSE TYPE

\begin{tabular}{lccc}
\hline Purpose Type & Clarity & Compatibility & Purposefulness \\
\hline Advocating & $\mathbf{4 . 0 6}$ & 3.74 & $\mathbf{3 . 9 0}$ \\
Basic Needs & 3.45 & 3.07 & 3.27 \\
Benevolence & 3.90 & 3.75 & 3.82 \\
Career & 3.88 & $\mathbf{3 . 8 6}$ & 3.87 \\
Family & 3.76 & 3.41 & 3.59 \\
Personal growth & 3.69 & 3.52 & 3.60 \\
Principled life & 3.94 & 3.64 & 3.79 \\
Quality life & 3.48 & 3.25 & 3.37 \\
\hline
\end{tabular}

Finally, we examined the impact of purpose and purposefulness on work engagement and organizational commitment. Table 8 reports the correlations of purposefulness and the two factors with the two outcome measures. All the correlations are strong and statistically significant, $p \mathrm{~s}<.001$. Between the two factors, compatibility has higher correlations with the two outcome measures than clarity.

TABLE 8

CORRELATIONS OF PURPOSEFULNESS WITH ENGAGEMENT AND COMMITMENT

\begin{tabular}{lcc}
\hline & Work Engagement & Organizational Commitment \\
\hline Clarity & $.36^{* *}$ & $.30^{* *}$ \\
Compatibility & $.47^{* *}$ & $.53^{* *}$ \\
Purposeful & $.47^{* *}$ & $.48^{* *}$ \\
\hline$* * p<001$ & &
\end{tabular}

** $p<.001$

ANOVA were conducted comparing different types of purpose on work engagement and organizational commitment. As shown in Table 9 , mean differences on work engagement were statistically significant $\left(F_{(7}\right.$, $\left.{ }_{795)}=4.98, p<.001\right)$. Individuals having benevolence, advocating, and career purposes are more engaged with their work than those who pursue basic needs and quality life goals. Mean differences on organizational commitment were not statistically significant $\left(F_{(7,795)}=1.61, p>.05\right)$. But once again, when individuals focus on basic needs and quality life goals, they appear to be less committed to their organization.

TABLE 9

MEANS ON ENGAGEMENT AND COMMITMENT BY PURPOSE TYPE

\begin{tabular}{lrc}
\hline Purpose Type & Work engagement & Organizational commitment \\
\hline Advocating & $\mathbf{5 4 . 2 \%}$ & $41.6 \%$ \\
Basic Needs & $35.5 \%$ & $32.7 \%$ \\
Benevolence & $\mathbf{5 5 . 6 \%}$ & $45.9 \%$ \\
Career & $\mathbf{5 1 . 9 \%}$ & $36.2 \%$ \\
Family & $43.0 \%$ & $41.5 \%$ \\
Personal growth & $50.3 \%$ & $41.5 \%$ \\
Principled life & $49.3 \%$ & $42.2 \%$ \\
Quality life & $39.3 \%$ & $34.7 \%$ \\
\hline
\end{tabular}

Note: $\%$ are population norm referenced percentile scores. 


\section{Summary and Discussion}

Study II not only supported the two-factor model of purposefulness at work, but also provided initial validity evidence. When individuals perceived purposefulness at work, they were more engaged and committed. The most intriguing finding from Study II is the differential impact of different purposes. All purposes don't work equally. Some purposes engender higher level of purposefulness at work than other purposes. This finding suggests that engagement and commitment is only partially influenced by organizational and management practices. There also exists individual differences, such as the type of personal purpose people enact at work. Employees are not passive job recipients. While designing features impact the objective characteristics of a job, people also reconstrue their work in relation to their personal purposes. Reinforcing the meaning of life literature, purposes differ along the self-others continuum. They also refer to different time orientations. Some purposes aim at a definite end state, reflecting what to go after. They appear to be time bounded. Other purposes only point to a direction without an end state, indicating how to go there. They are timeless and enduring. These subtle differences further justify the specification of purpose content for better understanding of its impact at work.

\section{GENERAL DISCUSSION}

Meaning and purpose have increasing recognition among organizational scholars. Traditional research on meaningful work has a partial focus on the source of meaningfulness. The review work by Rosso et al. (2010) integrated theories from different disciplines. These authors called for investigation of mechanisms and sources of meaning that implicate a broader set of psychological processes. This research turns the attention to purpose, one of the critical personal factors that influence perception of meaning and meaningfulness. Through qualitative data collection and analysis, a taxonomy that identifies eight types of purpose was established. The robustness of this taxonomy was tested by its relationships with the sense of purposefulness at work, the self-others continuum, the timeframe, and its impact on employee engagement and organizational commitment.

\section{Theoretical Implications}

The first contribution of this study is the establishment and validation of a purposefulness at work survey. Purposefulness has two components - clarity and compatibility. The correlation between Compatibility and Clarity was $r=0.51$ in Study I and $r=0.56$ in Study II. A number higher than 0.70 usually suggests conceptual redundancy. These correlations are less than 0.70 , suggesting that the two scales assess two different but related constructs. It is noticeable that compatibility was scored lower than clarity in both studies. It appears that a degree of clarity is a pre-requisite for high levels of compatibility. Individuals have to be aware and clear about their purposes before they can determine if their purposes are compatible with and supported by the employment situations.

On the other hand, compatibility has higher correlations with work engagement and organizational commitment than does clarity. Having a purpose is important, even so is the perceived compatibility. Compatibility is a subjective interpretation. Techniques such as cognitive reframing, recalibrating and refocusing can help individuals transform the meaning of their work toward more desired appraisals (Ashforth \& Kreiner, 1999). Organizations could also support employees' job-crafting effort to increase the match between the work and personal identity. By allowing authentic self-expressing, employees can see and build the connection between individual purposes and the organization's grand mission. A janitor in NASA then could proudly say "I'm not mopping the floors, I'm putting a man on the moon" (Carton, 2018, p. 354).

Purpose was measured and discussed in the abstract in the literature. We need to pay more attention to the origin of purposefulness - what really gives rise of the feeling of being purposeful. For instance, purposefulness has been linked to psychological well-being, physical health, and job performance. Then what can people do to enhance purposefulness? Do all purposes generate the same impact? Answers to these questions require the understanding and specification of the content of purpose. The other significant 
contribution to the literature is the development of a purpose taxonomy. To our knowledge, this is the first empirical study that has built a taxonomy of purpose using adult participants.

The fact that eight types of purpose emerged from this study suggests that organizations and leaders should not assume that all employees would respond to their interventions in the same way. Employees do not passively receive meaning and purpose given by others. They possess orientation systems to proactively make meaning out of the situations they live in. Organizations and leaders therefore need to pay attention to diverse motives of individuals. Only $6 \%$ of the employees in our sample have career as their top purpose. Even fewer selected basic needs $(2 \%)$. To the contrary, many participants in this study focus on benevolence, family, and living according to certain principles. If these statistics represent the typical workforce, it opens new and different ideas about how organizations can engage employees. Career systems still matter. But perhaps opportunities to allow and support employees serving others and their families can energize people and instill passion to a higher level.

Different personal purposes are related to purposefulness to different degrees. In general, highly purposeful individuals tend to be more self-transcendent than self-focused. This finding appears to support the notion that individuals may try to compensate for their lack of purposefulness in life by the singleminded pursuit of pleasure or an obsessive striving for material goals (Dollarhide, 1997). Purposes also have different impact on work engagement. Others-focused purposes, such as benevolence and advocating for a cause, have more positive relations with both purposefulness and work engagement. This finding is consistent with previous research that has shown the beneficial impact of the prosocial motives (Dik et al., 2012). This does not necessarily mean some purposes can be ignored in favor of others. Scholars emphasized the balanced approach to meaning and meaningfulness (Lips-Wiersma \& Morris, 2009; Rosso et al., 2010). A lopsided focus on self-oriented purposes could lead to the experience of inner emptiness. Similarly, pursing other-oriented purposes without adequate attention on personal well-being may result in mental exhaustion and burnout. A balanced approach is likely to generate lasting positive impact for individuals and their organizations.

\section{Practical Implications}

Organizations are spending hundreds of millions of dollars on employee engagement programs, yet scores on engagement surveys have remained consistently low (Morgan, 2017). Existing employee engagement programs tend to follow the tradition of job characteristic model (Hackman \& Oldham, 1976). It is based on the assumption that organizations and managers can manage and manipulate the job and the environment to drive positive employee experience. Wrzesniewski and Dutton, however, have pointed out that people can proactively shape and mold their experience on the job (2001). In the sense-making process, people also listen to internal signals (Lips-Wiersma \& Morris, 2009). The current research found a significant relationship between purposefulness at work and employee engagement, suggesting an alternative approach to employee engagement. Instead of intervening and manipulating the work and the environment, organizations perhaps can give employees more freedom to follow their hearts. When employees are supported for authentic self-expression, they are more engaged, customers are more satisfied (Cable et al., 2013). We live in an era where self-management seems to become the norm. Rather than taking a top-down approach to design and implement programmatic engagement packages that tend to be applied to many, companies and managers can facilitate and support individuals to become themselves and express their personal purposes.

This research found that self-transcendent purposes engender higher level of purposefulness and employee engagement than do self-oriented purposes. Opportunities should be created to channel such pursuits. This requires organizations and leaders to reconsider the relationship between business and society. In a New York Times Magazine article published on Sept. 13, 1970, American economist Milton Friedman famously argued that businesses' sole purpose is "to use its resources and engage in activities designed to increase its profits." This perspective has permeated management thinking for a long time. But the moral basis of that business doctrine has been under significant attack in recent years. Business organizations have been criticized for treating the employment relationship as an economic exchange relationship that promotes self-interest (Quinn \& Thakor, 2019). The current research revealed that 
employees are not necessarily self-centered. They care about the impact beyond the boundary of the organization. It's time to bring business and society back together. Starting with the very fundamentals, companies perhaps need to reassess their organizational mission and vision statements to make sure the social element has been incorporated. To be aligned with their missions and visions, companies also need to reconceive their operational model so that their business creates both economic and social values (Porter \& Kramer, 2011). Efforts such as communication and performance feedback can be implemented to help employees see the connection between their daily activities and the social impact. When such link is less clear due to the nature of the business, companies can allocate resources to support employees' involvement in community services.

\section{Limitations and Conclusion}

Some limitations need to be noted. First, this research used cross-sectional data. Reciprocal relationships could exist between meaning and purpose and outcome measures. The direction of the relationship between purposefulness and work engagement and organizational commitment could be tested with longitudinal research design in the future.

Second, this research asked participants to select one purpose type that characterizes their personal purposes. An individual could have simultaneously multiple purposes. By forcing individuals select only one, we missed the opportunity to investigate how different purposes jointly impact purposefulness and performance outcomes. Future research could use different survey methods to assess the degree to which each purpose is endorsed by people, and how different purposes interact to influence individual and organizational outcomes.

Third, we relied mostly on the online platform to recruit participants. We have less concern on this data collection methodology as empirical research has supported the data quality of online surveys (Clifford et al., 2015; Levay et al., 2016). But participants were recruited from different unknown organizations. This research argues that employee experience is greatly influenced by individual orientation system and personal purpose, but it doesn't exclude the effect of leadership, organizational culture, and other external factors. In fact, one could argue that the relationship between personal purpose and employee engagement and organization commitment should be moderated by the strength of the situation because strong situations place more constraints on individuals' behavior than weak situations. Future research may try to contextualize the impact of purpose and purposefulness by either collecting data on organizational factors or contrasting different types of organizations.

Despite these limitations, the present study advances meaning and purpose literature in the work domain. Organizational research in meaning and purpose is still in its adolescence. There remains a world of possibilities for organizational scholars to strengthen this area of study. Modern culture encourages personal fulfilment. Younger generations are particularly raised to believe that they can be anything they want to be. Findings from this research reveal what purposefulness at work denotes. Being purposeful at work means both perceiving the purpose and seeing the congruence with the surroundings. The taxonomy of purpose yielded insights into the connection between purpose and purposefulness. All purposes are not equal. Being specific about the content of purpose allows us to deepen our understanding of how people enact purpose at work and what benefits different purposes can create. 


\section{REFERENCES}

Arnold, K.A., Turner, N., Barling, J., Kelloway, E.K., \& McKee, M.C. (2007). Transformational leadership and psychological well-being: The mediating role of meaningful work. Journal of Occupational Health Psychology, 12, 193-203.

Ashforth, B.E., \& Kreiner, G.E. (1999). "How can you do it?": Dirty work and the challenge of constructing a positive identity. Academy of Management Review, 24, 413-434.

Bagozzi, R.P., Bergami, M., \& Leone, L. (2003). Hierarchical representation of motives in goal setting. Journal of Applied Psychology, 88, 915-943.

Baumeister, R.F. (1991). Work, work, work, work. Meanings of life (pp. 116-144). New York: The Guilford Press.

Berg, J.M., Grant, A.M., \& Johnson, V. (2010). When callings are calling: Crafting work and leisure in pursuit of unanswered occupational callings. Organization Science, 21(5), 973-994.

Berg, J.M., Wrzesniewski, A., \& Dutton, J.E. (2010). Perceiving and responding to challenges in job crafting at different ranks: When proactivity requires adaptivity. Journal of Organizational Behavior, 31, 158-186.

Brown, A., \& Maydeu-Olivares, A. (2011). Item response modeling of forced-choice questionnaires. Educational and Psychological Measurement, 71(3), 460-502.

Burger, D.H., Crous, F., \& Roodt, G. (2012). Exploring a model for finding meaning in the changing world of work (part 2). SA Journal of Industrial Psychology, 38(1), 49-59-10.

Cable, D.M., Gino, F., \& Staats, B.R. (2013). Breaking them in or eliciting their best? Reframing socialization around newcomers' authentic self-expression. Administrative Science Quarterly, 58(1), 1-36.

Carton, A.M. (2018). "I'm not mopping the floors, I'm putting a man on the moon": How NASA leaders enhanced the meaningfulness of work by changing the meaning of work. Administrative Science Quarterly, 63(2), 323-369.

Chulef, A.S., Read, S.J., \& Walsh, D.A. (2001). A hierarchical taxonomy of human goals. Motivation and Emotion, 25(3), 191-232.

Clifford, S., Jewell, R.M., \& Waggoner, P.D. (2015). Are samples drawn from Mechanical Turk valid for research on political ideology. Research and Politics, 2(4), 1-9.

Cohen-Meitar, R., Carmeli, A., \& Waldman, D.A. (2009). Linking meaningfulness in the workplace to employee creativity: The intervening role of oganizational identification and positive psychological experiences. Creativity Research Journal, 21(4), 361-375.

Crumbaugh, J.C. (1968). Cross-validation of purpose in life test based on Frankl's concepts. Journal of Individual Psychology, 24, 74-81.

Damon, W., Menon, J., \& Bronk, K.C. (2003). The development of purpose during adolescence. Applied Developmental Science, 7, 119-128.

Dik, B.J., Eldridge, B.M., Steger, M.F., \& Duffy, R.D. (2012). Development and validation of the Calling and Vocation Questionnaire (CVQ) and Brief Calling Scale (BCS). Journal of Career Assessment, 20, 242-263.

Dimitrov, D. (2012). Sources of meaningfulness in the workplace: A study in the US hospitality sector. European Journal of Training and Development, 36(2/3), 351-371.

Dollarhide, C.T. (1997). Counseling for meaning in work and life: An integrated approach. Journal of Humanistic Education and Development, 35(4), 178-187.

Festinger, L. (1957). A theory of cognitive dissonance. Evanston, IL: Row, Peterson.

Frankl, V. (1959). Man's search for meaning. Cutchogue, NY: Buccaneer Books, Inc.

Frey, C.B., \& Osborne, M.A. (2013). The future of employment: How susceptible are jobs to computerization? Oxford Martin School Working Paper. Retrieved from https://www oxfordmartin.ox.ac.uk/downloads/academic/The_Future_of_Employment.pdf

Friedman, M. (1970, September 13). The social responsibility of business is to increase its profits. New York Time, Section SM, p.17. 
George, L.S., \& Park, C.L. (2016). The multidimensional existential meaning scale: A tripartite approach to measuring meaning in life. The Journal of Positive Psychology, 12(6), 613-627.

George, L.S., \& Park, C.L. (2017). Meaning in life and violations of beliefs and goals: Reciprocal relations among individuals with congestive heart failure. Anxiety, Stress, \& Coping, 30(3), 282 289.

Hackman, J.R., \& Oldham, G.R. (1976). Motivation through the design of work: Test of a theory. Organizational Behavior and Human Performance, 16, 250-279.

Heintzelman, S., \& King, L.A. (2014). Life is pretty meaningful. American Psychologist, 69(6), 561-574.

Heintzelman, S.J., Trent, J., \& King, L.A. (2013). Encounters with objective coherence and the experience of meaning in life. Psychological Science, 24(6), 991-998.

Herbert, W. (2010). On second thought: Outsmarting your mind's hard-wired habits. New York: Crown Publishers.

Kahn, W.A. (1990). Psychological conditions of personal engagement and disengagement at work. Academy of Management Journal, 33(4), 692-724.

Kendall, M. (2019). Workplace spirituality and the motivational impact of meaningful work: An experimental study. Journal of Organizational Psychology, 19(2), 74-92.

King, L.A. (2012). Meaning: Effortless and ubiquitous. In M. Mikulincer \& P. Shaver (Eds.), Meaning, mortality, and choice: The social psychology of existential concerns (pp. 129-144). Washington, D.C.: APA.

Klein, H.J., Wesson, M.J., Hollenbeck, J.R., \& Alge, B.J. (1999). Goal commitment and the goal-setting process: Conceptual clarification and empirical synthesis. Journal of Applied Psychology, 84(6), 885-896.

Levay, K., Freese, J., \& Druckman, J.N. (2016, January-March). Demographic and political composition of Mechanical Turk samples. SAGE Open, pp. 1-17.

Lewis, J.L. (2015). Korn Ferry four dimensional executive assessment. Los Angeles, CA: Korn Ferry.

Lips-Wiersma, M., \& Morris, L. (2009). Discriminating between 'meaningful work' and the 'management of meaning'. Journal of Business Ethics, 88(3), 491-511.

Locke, E.A., \& Latham, G.P. (1990). A theory of goal setting and task performance. Englewood Cliffs, NJ: Prentice Hall.

May, D.R., Gilson, L., \& Harter, L.M. (2004). The psychological conditions of meaningfulness, safety and availability and the engagement of the human spirit at work. Journal of Occupational and Organizational Psychology, 77, 11-37.

Michaelson, C. (2005). "I want your shower time!'”: Drowning in work and the erosion of life. Business and Professional Ethics Journal, 24, 7-26.

Morgan, J. (2017). Why the millions we spend on employee engagement buy us so little. Harvard Business Review. Retrieved March 20, 2020, from https://hbr.org/2017/03/ why-the-millions-wespend-on-employee-engagement-buy-us-so-little

Park, C.L. (2010). Making sense of meaning literature: An integrative review of meaning making and its effects on adjustment to stressful life events. Psychological Bulletin, 136(2), 257-301.

Porter, M.E., \& Kramer, M.R. (2011). Creating shared values: How to reinvent capitalism and unleash a wave of innovation and growth. Harvard Business Review, 89(1-2), 62-77.

Pratt, M.G., \& Ashforth, B.E. (2003). Fostering meaningfulness in working and at work. In K.S. Cameron, J.E. Dutton, \& R.E. Quinn (Eds.), Positive organizational scholarship (pp. 309-327). San Francisco: Berrett-Koehler Publishers, Inc.

Pratt, M.G., Rockmann, K.W., \& Kaufmann, J.B. (2006). Constructing professional identity: The role of work and identity learning cycles in the customization of identity among medical residents. Academy of Management Journal, 49(2), 235-262.

Quinn, R.E., \& Thakor, A.V. (2019). The economics of higher purpose. Oakland, CA: Berrett-Koehler Publishers, Inc. 
Reker, G.T., \& Wong, P.T.P. (1988). Aging as an individual process: Toward a theory of personal meaning. In J.E. Birren \& V.L. Bengtson (Eds.), Emergent theories of aging (pp. 214-246). New York, NY: Springer.

Rosso, B.D., Dekas, K.H., \& Wrzesniewski, A. (2010). On the meaning of work: A theoretical integration and review. Research in Organizational Behavior, 30, 91-127.

Rothausen, T.J., \& Henderson, K.E. (2019). Meaning-based job-related well-being: Exploring a meaningful work conceptualization of job satisfaction. Journal of Business and Psychology, 34(3), 357-376.

Rudolph, C.W., Lavigne, K.N., Katz, I.M., \& Zacher, H. (2017). Job crafting: A meta-analysis of relationships with individual differences, job characteristics, and work outcomes. Journal of Vocational Behavior, 102, 112-138.

Ryff, C.D. (1989). Happiness is everything, or is it? Explorations on the meaning of psychological wellbeing. Journal of Personality and Social Psychology, 57, 1069-1081.

Sonenshein, S., \& Dholakia, U. (2012). 'Explaining employee engagement with strategic change implementation: A meaning-making approach. Organization Science, 23, 1-23.

Steger, M.F., Dik, B.J., \& Duffy, R.D. (2012). Measuring meaningful work: The Work and Meaning Inventory (WAMI). Journal of Career Assessment, 20, 322-337.

Steger, M.F., Frazier, P., Oishi, S., \& Kaler, M. (2006). The meaning in life questionnaire: Assessing the presence of and search for meaning in life. Journal of Counseling Psychology, 53, 80-93.

Updegraff, J.A., Silver, R.C., \& Holman, E.A. (2008). Searching for and finding meaning in collective trauma: Results from a national longitudinal study of the 9/11 terrorist attacks. Journal of Personality and Social Psychology, 95, 709-722.

Wrzesniewski, A. (2003). Finding positive meaning in work. In K.S. Cameron, J.E. Dutton, \& R.E. Quinn (Eds.), Positive organizational scholarship. San Francisco: Berrett-Koehler Publishers, Inc.

Wrzesniewski, A., \& Dutton, J.E. (2001). Crafting a job: Revisioning employees as active crafters of their work. Academy of Management Review, 26(2), 179-201.

Yeager, D.S., \& Bundick, M.J. (2009). The role of purposeful work goals in promoting meaning in life and in schoolwork during adolescence. Journal of Adolescent Research, 24, 423-452. 